Veterinary Research 12 (2): 10-18, 2019

ISSN: $1993-5412$

(C) Medwell Journals, 2019

\title{
Effect of Short Term Food Deprivation and Re-Feeding on Growth, Feeding and Biochemical Body Composition in Sobaity Fish, Sparidentex hasta
}

\author{
${ }^{1}$ Molayemraftar Taravat, ${ }^{2}$ Kochanian Preeta, ${ }^{2}$ Zakeri Mohammad, ${ }^{2}$ Yavari Vahid and \\ ${ }^{2}$ Moosavi Seyed Mohammad \\ ${ }^{1}$ Department of Clinical Sciences, Faculty of Veterinary Medicine, \\ Shahid Chamran University of Ahvaz, Ahvaz, Iran \\ ${ }^{2}$ Department of Fisheries, Faculty of Marine Natural Resources, \\ Khoramshahr Marine Science and Technology University, Khorramshahr, Iran \\ Taravat.molayemraftar@yahoo.com,+986324234725
}

\begin{abstract}
In this study, the effects of different food deprivation and re-feeding has been examined on growth, nutrition, body composition and composition of liver. The groups consisted of the constant control over the experimental period until full feeding was twice daily, groups of 2-8 days of food deprivation followed by 8-32 days of re-feeding in repeated cycles during 80 days. At the end of expriment, the daily food intake, ash and moisture content of the body composition were significantly affected by alternating periods of food deprivation and re-feeding $(\mathrm{p}<0.05)$. But alternating periods of food deprivation and re-feeding are not effective on weight gain, specific growth rate, condition factor, feed conversion efficiency, protein efficiency ratio, lipid and protein content of body omposition and content of the liver glycogen and lipid ( $p>0.05)$. After the feeding period, roups that have experienced food deprivation showed complete compensatory growth. Because growth in these groups showed no significant difference compared with the control group. The study establish that, sobaity fish have ability to achive optimal growth after food deprivation and re-feeding periods.
\end{abstract}

Key words: Food deprivation, re-feeding, growth, feed intake, body composition, Sparidentex hasta

\section{INTRODUCTION}

Different species of fish confronted with food deprivation naturally. This phenomenon occurs, for example, during the Winter when long-term migration takes place for spawning or when food in the living area is reduced for various reasons. These changes are seasonal but can be changed and continue from a few weeks to several months. These food deprivation periods can cause a severe decrease in the energy resources of fish body and result in the exhaustion of fish tissues to survive (Frape, 1998). In the way that in short-term food deprivation the viscera and intestines lipid start to move as an energy source and water replaces with muscle fat. When the food resources come back to their normal state, muscle weight, liver glycogen and muscles fat also decrease (Jobling, 1994). On the other hand during the period of food deprivation, metabolism of body reduces, so that, the reduction in weeks after food deprivation is lower than in the weeks prior to food deprivation. It is also believed that the reduction of metabolism rate is continued for a certain period after the removal of undesirable conditions (Hornick et al., 2000). The response of some fish during food deprivation and re-feeding is hyperphagia which increases feed efficiency and improves the growth rate. These responses act as a management tool and increase the benefits of aqua culture activities to compensatory growth studies. Also, feeding strategies that stimulate the compensatory growth in fish can be considered as other useful ways to increase growth and feed efficiency (Gaylord and Gatlin, 2000). Compensatory growth has been studied in a wide range of fish species such as, salmonids (Johansen et al., 2001; Nikki et al., 2004; Sevgili et al., 2013a b; Tasbozan et al., 2016), Nile tilapia (O. niloticus) (Wang et al., 2009), hybrid tilapia (O. mossambicus* ${ }^{*}$. niloticus) (Wang et al., 2000, 2005), gibel carp (Carrasius auratus gibelio) (Qian et al., 2000; Xie et al., 2001), Chinese sturgeon (Acipenser sinensis) (Liu et al., 2011), hybrid striped bass (Morone chrysops*Morone saxatilis) (Turano et al., 2007, 2008) and other pecies. These feeding strategies, for example, can lead to improvement in time management three of employees, water quality and feeding activity of fish (Gaylord and Gatlin, 2000; Eroldogan et al., 2008; Guzel et al., 2011).

Corresponding Author: Molayemraftar Taravat, Department of Clinical Sciences, Faculty of Veterinary Medicine, Shahid Chamran University of Ahvaz, Ahvaz, Iran, Taravat.molayemraftar@yahoo.com, +986324234725 
The cost of formulated food and man power for the fish feeding is considered as a large amount of the total cost for cultivation of carnivorous fish. So, improvement in feeding strategies has great importance in cultivation of carnivorous fish. Sobaity fish is from a carnivorous species and mostly feeds on invertebrates and crustaceans (Abdessalaam, 1995). This fish is found in shallow and deep water in the Persian Gulf and the coast of India and it has great commercial importance (Fischer and Bianchi, 1984). The objective of the present study were to determine feeding time patterns in growth, food intake and body composition of sobaity fish in short-term food deprivation cycle protocols and re-feeding.

\section{MATERIALS AND METHODS}

Fish rearing and experimental design: All the practical and administrative procedures of this study were conducted from October 2012 to January 2013 in the Emam Khomeyni fisheries research station. A total of 300 sobaity fry with the average weight of $28.47 \pm 0.24 \mathrm{~g}$ were selected. Sobaity fry distributed randomly among 12 round fiberglass tanks with the containing capacity of $300 \mathrm{~L}$ each. At the time of experiment, the containing water of each tank was $250 \mathrm{~L}$ ( 25 fry per each tank). In order to provide oxygen for fry an air stone placed in each tank. To keep the temperature in favorable state, each tank equipped with a thermal controlling system ( $350 \mathrm{~W}$ ha). In order to be adapted with concentrate food, 2 weeks before the beginning of experiment, fry were fed on concentrate food. To review the effects of food deprivation periods and re-feeding on growth function, feeding, body composition, lipid and glycogen of liver were considered in 3 treatments with 3 times repetitions (Fig. 1). The duration of this study was 80 days. For this purpose, 4 groups were designed.

The three groups were periodically starved Fig. 1; 2 days food deprivation followed by 8 days re-feeding $\left(\mathrm{T}_{1}\right), 4$ days food deprivation followed by 16 days re-feeding $\left(\mathrm{T}_{2}\right)$ and 8 days food deprivation followed by 32 days re-feeding $\left(\mathrm{T}_{3}\right)$. There was another group for the control group that were fully fed during all steps of experiment. At the end of food deprivation period, all groups were fully fed. In order to have equal food distribution, less water turbulences and an increase in perdurability of food in water, during the time offeeding, aerating to the tanks were stopped and after $20 \mathrm{~min}$ re-aerating were performed. Also, there were no feeding in biometry and sampling days. Temperature, $\mathrm{pH}$ and salinity were measured daily. Temperature were measured by a

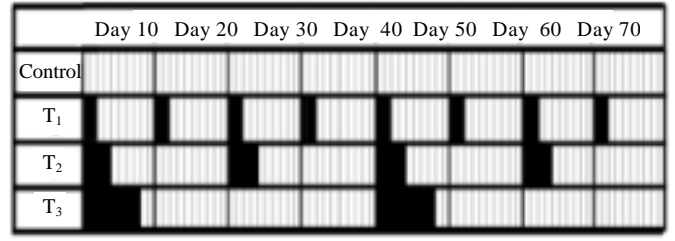

Fig. 1: Food deprivation and re-feeding groups during the experimental period (white $=$ feeding and black $=$ food deprivation)

digital portable thermometer, $\mathrm{pH}$ and salinity of water were measured by respectively, $\mathrm{pH}$ meter and salinometer. oxygen also measured weekly.

Growth and feed efficiency parameters: During the experiment, fish mortality were recorded and dead individuals removed from the tanks without adding any replacement. Biometry in individuals were taken every 10 days (weight with the accuracy of $0.1 \mathrm{~g}$, total length and the standard lenght with the accuracy of $0.1 \mathrm{~cm}$ ). After every biometry, growth indexes like Weight gain (Wg), Special Growth Rate (SGR), Condition Factor (CF), Protein Efficiency Rate (PER), Food Change Rate (FCR), Food Change Efficiency (FCE) and Daily Food Intake (DFI\%) were measured (Kankanen and Pirhonen, 2009; Houde and Schekter, 1981).

Sampling and chemical analysis: At the beginning, middle and end of period, 6 individuals were selected randomly from each group for carcass composition analysis. Sampling were taken from the first group ( 2 days of food deprivation) in the days of 2-80 from second group ( 4 days of food deprivation) in the days of 4-80 and from the third group ( 8 days of food deprivation) in the days of $8-80$ and from the control group on all the days mentioned. Measurements of carcass compositions were performed according to AOAC (1990). The moisture was measured by oven drying at $105^{\circ} \mathrm{C}$ for $24 \mathrm{~h}$. Ash content was determined by incineration in German carbolite furnace for $4 \mathrm{~h}$ at $550^{\circ} \mathrm{C}$. To measure the crude protein, the Kjehldal method and the automatic Kjeldahl analyzer (BUCHI 3700 analyser unit K Sweden) were used. In order to measure lipid an automatic Soxhlet device was used in the construction of Sweden and lipid was extracted by petroleum ether extraction. After removing liver's tissue the tissue were transferred to laboratory by a liquid nitrogen tank and were transferred to a freezer at $-8^{\circ} \mathrm{C}$. Liver glycogen and lipid were measured by respectively, Lo et al. (1970) and Frings et al. (1972). 
Calculation and statistical analysis: Statistics were performed using the SPSS Computer Software Version 15.0 for Windows. The normality of distribution of variables was tested using Kolmogorov-Smirnov test. The possible differences in the variables among the groups were tested using one-way ANOVA. Post hoc comparisons between means were tested using Tukey test. Data were expressed as mean \pm Standard Error (SE) and differences were considered significant at the $\mathrm{p}<0.05$ level.

\section{RESULTS AND DISCUSSION}

During the experiment period, temperature was $24.81 \pm 1.34^{\circ} \mathrm{C}$ and $\mathrm{pH}$ was $7.64 \pm 0.5$.

Growth and feed efficiency parameters: The results of food deprivationthe and re-feeding on the growth and feed efficiency parameters in Sparidentex hasta are shown in Fig. 2-4. There were no significant difference in the initial body weight between groups $(p>0.05)$. At the end of experiment there were no significant differences in WG, SGR, CF, FCE and PER between different groups ( $>0.05$ ). But there were significant differences in DFI between $\mathrm{T}_{3}$ group compared to control group at 80 days $(\mathrm{p}<0.05)$.

Carcass compositions and liver glycogen and lipid: The results of food deprivationthe and re-feeding on carcass compositions in Sparidentex hasta are shown in Fig. 5. According to the results, food deprivation and re-feeding had a significant effect on body protein content in $\mathrm{T}_{1}$ and $\mathrm{T}_{3}$ at the end of experiment $(\mathrm{p}<0.05)$. Content of body lipid in $T_{1}-T_{3}$ groups were significantly lower than that of control group $(\mathrm{p}<0.05)$. But there were no significant differences in content of ash and moisture between different groups of experiment $(p>0.05)$. At the end of

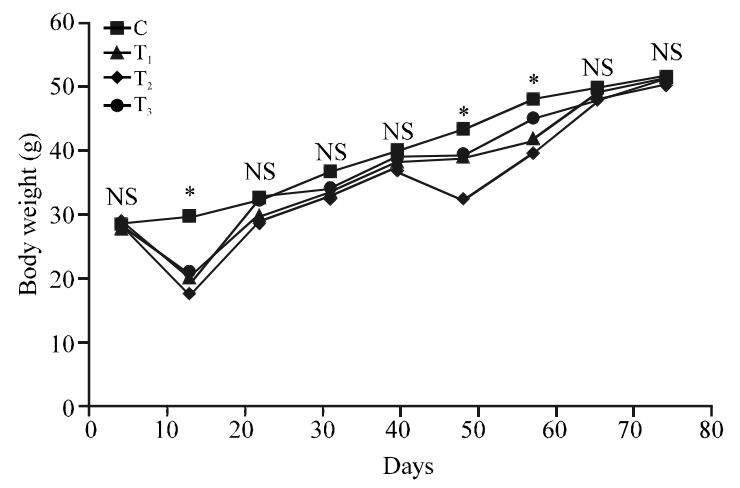

Fig. 2: Changes in body weight of sobaity fish in different groups during the experimental period experiment, food deprivation and re-feeding had not a significant effect on lipid and glycogen content of liver between different groups ( $\mathrm{p}>0.05)$ (Fig. 6).

Compensatory growth has been reported in a wide range of animal from insects (Metcalfe and Monaghan, 2001 ) to birds and mammals (Dobson and Holmes, 1984). Several studies have been conducted by researchers in the largest group of vertebrates, namely fish. In the first, the term "Compensatory growth" were used for mammals and later it was used for warm-blooded domestic animals (Wilson and Osbourn, 1960). Few research was done in relation to compensatory growth in fish aquaculture in the early 1990's when it was considered. Addition, studies of marine fishes are limited to only a few groups (Ali et al., 2003). Ability to compensate for growth retardation is an important adaptation that allows the fish in spite of variable and unpredictable environmental conditions to remain in mainstream. In addition, in the marine environment due to the abundance of food sources there is a greater chance of survival. This
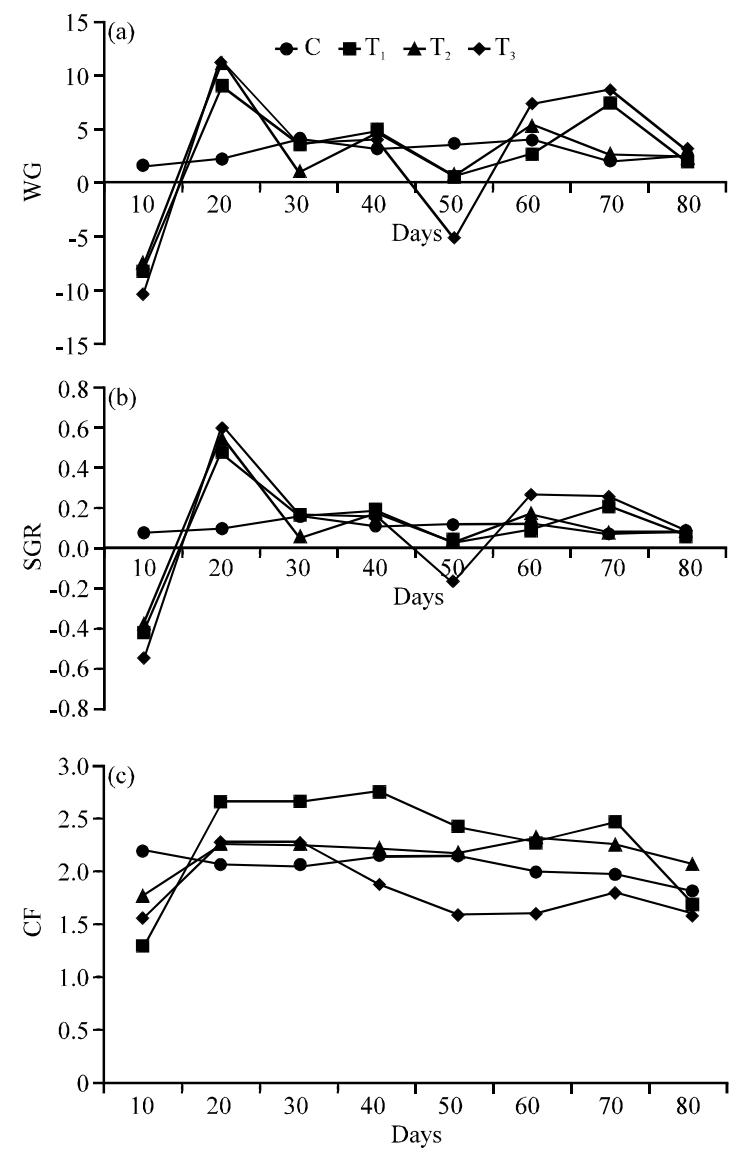

Fig. 3: Changes in: a) WG; b) SGR and c) CF of Sobaity fish in different groups during the experimental period 
compensation capability allows the fish to reach the minimum size required for these physiological changes at younger ages (Maclean and Metcalfe, 2001). Considering the lack of weight differences between fishes under various dietary deprivation at the end of the experiment it can be concluded that the fish have ability to adapt to the conditions of this experiment and have managed to reach the same weight of the fish in the control group. The results of this study were consistent with the finding of (Foss et al., 2009; Xie et al., 2001) regarding the lack of significant difference in the final weight of control fish and the fish that have been down under the different periods of food deprivation and re-feeding. If the amount of food is reduced the fish will first compromise with a new level of feeding by losing weight and by feeding on this new level will show a weight gain proportional to the nutritional requirements in the new condition. In addition, the lack of weight difference between treatments in the present study may be attributed to the reduction in body weight loss during food deprivation due to the ability of fish to reduce the amount of basal metabolism rate. Basal metabolic rate during food deprivation is mainly due to decreased metabolic rate and visceral mass.

Therefore, the weight loss during the period of hunger has decreased which together with re-feeding during the experiment caused the difference between the groups under food deprivation and the control group to decrease. In contrast, the results of this study are not consistent with the results of Heide et al. (2006), Nikki et al. and Wang et al. (2000). Differences in various studies can be due to the size and characteristics of the
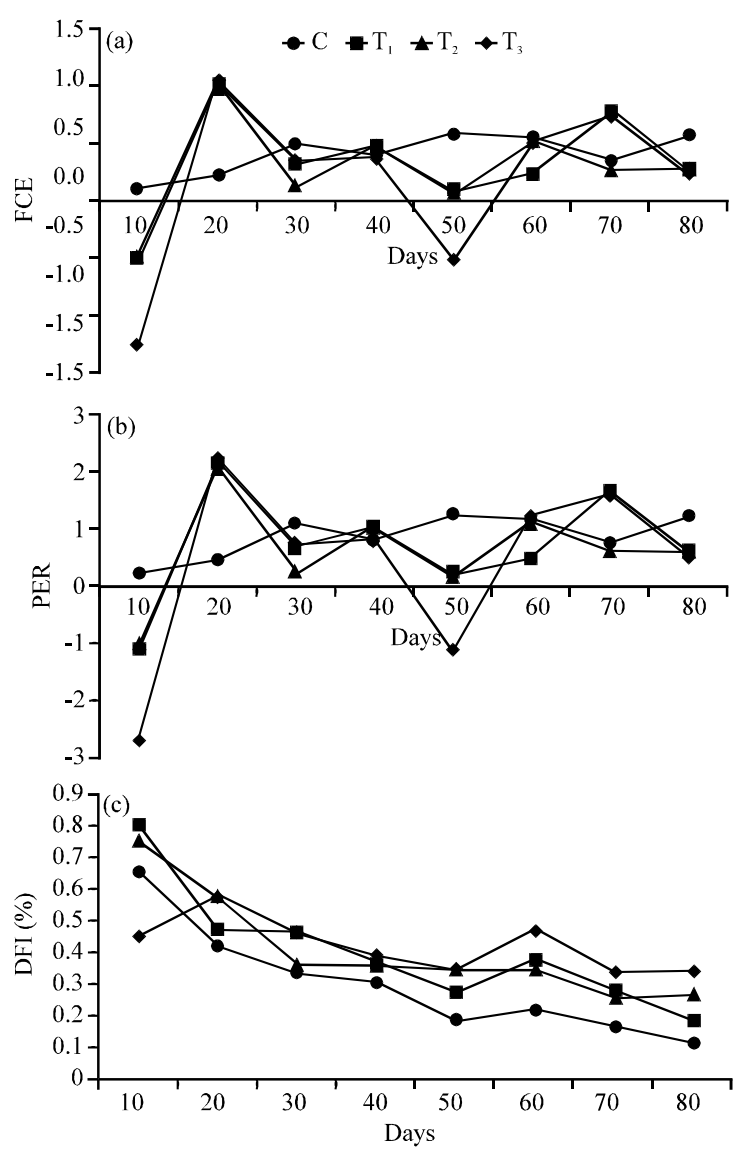

Fig. 4: Changes in: a) FCE; b) PER and d) DFI\% Sobaity fish in different groups during the experimental period
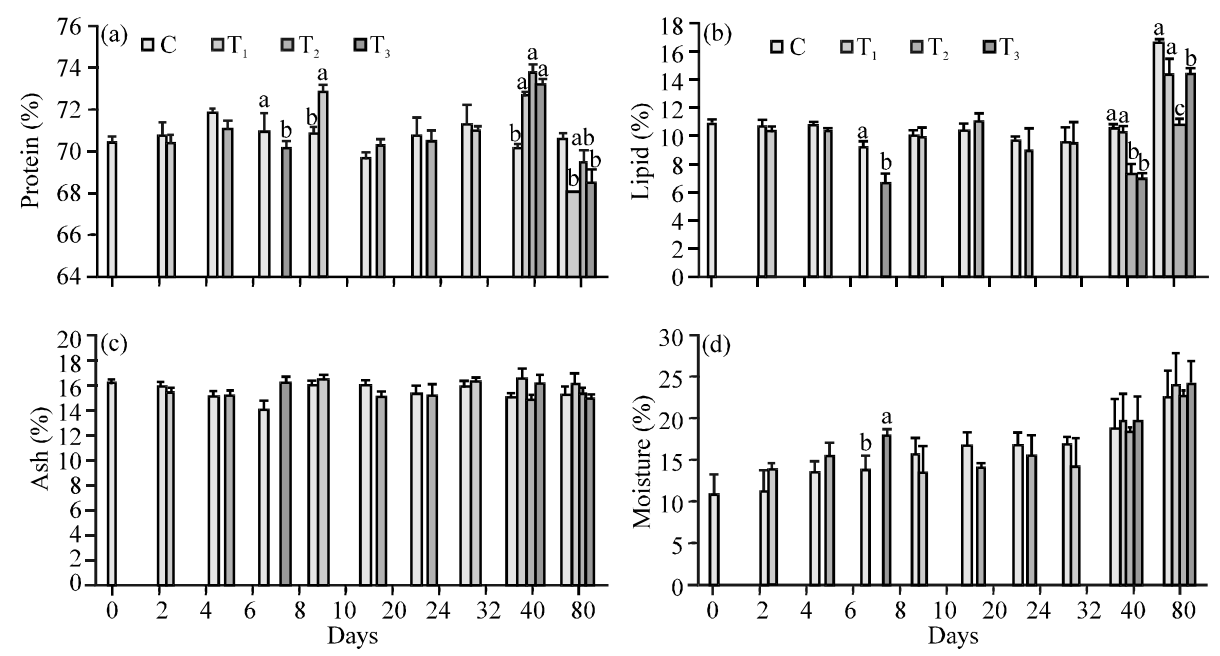

Fig. 5: Changes in: a) Crude protein; b) Crude lipid; c) Ash and d) Moisture contents of Sobaity fish in different groups after different periods of food deprivation and re-feeding during the experimental period. Means with different letters in the same column ar e significantly different $(\mathrm{p}<0.05)$ 

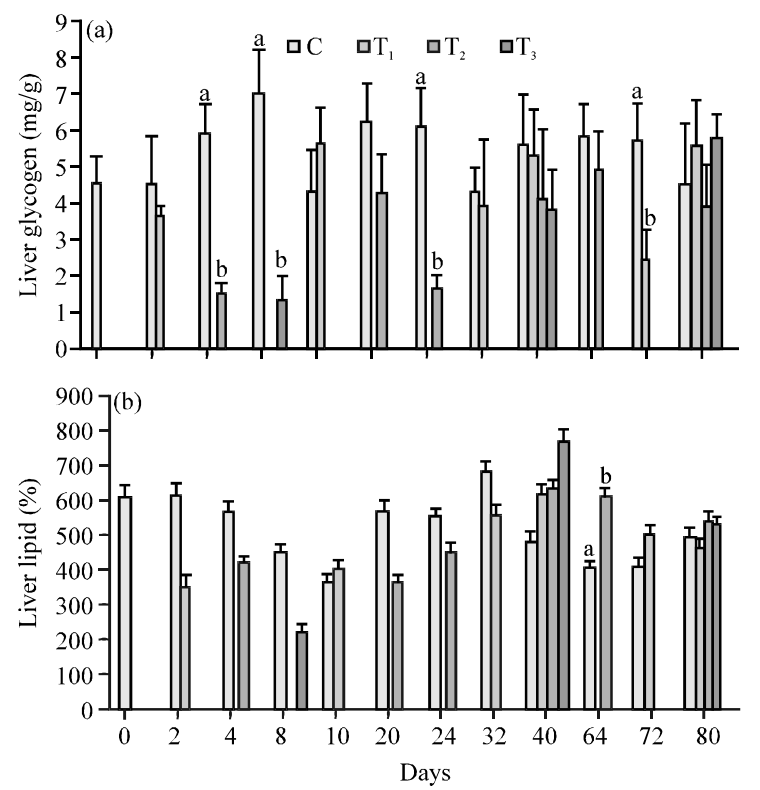

Fig. 6: Changes in: a) Liver glycogen and b) Lipid of Sobaity fish in different groups after different periods of food deprivation and re-feeding during the experimental period. Means with different letters in the same column are significantly different $(\mathrm{p}<0.05)$

species in relation to the compensatory response or to the difference in species characteristics. In this regard, Wang et al. (2000) and Zhu et al. (2004) stated that salmonids require more time for compensatory growth and in addition it has been proved that in order to induce compensatory responses in larger animals require longer periods of food deprivation than smaller animals (Foss et al., 2009). Also, the causes of the differences in the studies done 7 by the researchers with each other and with this research can be due to the severity of food deprivation, the severity of malnutrition or experimental (Jobling and Koskela, 1996) or different culture systems (Eroldogan et al., 2008). At the end of the experiment the specific growth rate did not show any significant difference among the fish exposed to food deprivation compared to the control group. Studies on gibel carp fish (Xie et al., 2001) and on Sparus aurata (Eroldogan et al., 2008) similar to the findings of this study, showed no significant differences in the specific growth rate of fish under food deprivation compared to the control group. Perhaps the reason for this may be attributed to the hierarchy of feeding in fish rearing tanks, since, fish show offensive behaviors after the elimination of food deprivation and most people are trying more to get food (Ali et al., 2003) also high individual variation may affect the effect of each group on growth efficiency (Sun et al., 2006).
Unlike to the views of these researchers Heide et al. (2006), Wang et al. (2000), Zhu et al. (2001), Tian and Qin $(2003,2004)$ reported contradictory results. In the studies of these researchers, the specific growth rates in the food deprivation groups were higher than the control group. The reason for this may be due to low energy costs during the period of food deprivation due to rest periods, increased feed efficiency, increased daily intake or a combination of all of these factors (Heide et al., 2006). Another possible reason for the high growth rate in food deprivation groups can be the reduction of metabolic rate in fish under food deprivation conditions due to their kinetic activity (Hayward et al., 2000; Jobling, 1980; Wieser et al., 1992).

Nikki et al. (2004) also, found a higher growth rate in some food-deprived groups in comparison with the control group and suggested the higher potential of these fish to compensate for starvation. At the end of experiment, the results of the condition factor showed no difference in any of the groups. Ali et al. (2003), Kankanen and Pirhonen (2009) in their studies, obtained similar results while Iqbal et al. (2006) were recorded a significant difference in this factor. The reason for these differences in these studies can be due to the severity of food deprivation, the severity of malnutrition or experiment conditions (Jobling and Koskela, 1996). Overall, according to the results of growth indices in this study it can be stated that the groups exposed to food deprivation showed a complete compensatory growth because the growth rate in these groups were no significant 8 difference compared to the control group. Over compensation has been reported in hybrid sun fish (Hayward et al., 1997) and channel catfish (Chatakondi and Yant, 2001). Full compensation were observed in Oncorhynchus mykiss (Nikki et al., 2004; Quinton and Blake, 1990), Leiocassis longirostris (Zhu et al., 2004), Phoxinus phoxinus (Russell and Wootton, 1992), Gibel carp (Xei et al., 2001), Lates calcarifer (Tian and Qin, 2003) with different protocols. In some studies, including (Wang et al., 2000; Jobling, 1980; Heide et al., 2006; Eroldogan et al., 2006; Wu et al., 2002) were reported partial compensation and the lack of compensation discussed by Hayward et al. (2000) study. The response to compensatory growth in fish can be related to the duration and severity of food deprivation before re-feeding (Bull and Metcalfe, 1997; Hayward et al., 1997). Also, studies on the response of fish to compensatory growth have shown that temperature (Dobson and Holmes, 1984; Maclean and Metcalfe, 2001), water quality (Quinton and Blake, 1990; Wicks and Randall, 2002), light period (Maclean and Metcalfe, 2001) and density (Hayward et al., 2000) affect the rate and severity of compensatory growth. One of the 
first mechanisms involved in compensatory growth responses is increasing food intake, known as hyperphagia phenomenon (Ali et al., 2003).

Hyperphagia is determined by increasing food intake and also the duration of daily feeding (Nicieza and Metcalfe, 1997). Hyperphagia has been proved during compensatory growth in fishes (Metcalfe and Thorpe, 1992). In the present study, the amount of daily food intake in $\mathrm{T}_{3}$ ( 8 days of food deprivation and 32 days re-feeding) was significantly higher than the control group and the numerical value of this index in other groups was higher than the control group, so, hyperphagia seemed almost clear. Increased food intake during compensatory growth has been reported for Arctic charr (Jobling and Miglavs, 1993), Atlantic halibut (Heide et al., 2006), Rainbow trout (Boujard et al., 2000; Quinton and Blake, 1990), Three-spined stickleback and Minnow (Zhu et al., 2001), Carassisus auratus gibelio and Leiocassis longirostris (Zhu et al., 2004), Leiocassis ongirostris ( $Z$ hu et al., 2005).

The results of body composition in this study showed that the short-term periods of food deprivation and re-feeding were ineffective on some parameters such as ash and moisture. These results are consistent with results of (Qinton and Blake, 1990; Tian and Qin, 2003, 2004; Ali et al., 2006; Eroldogan et al., 2008; Oh et al., 2007; Ribeiro and Tsuzuki, 2010; Liu et al., 2011; Adakly and Tasbozan, 2015). Because of this lack of difference in the amount of moisture is probably the inverse relationship between body lipid and water (with an equal volume of water substitution catabolized lipid). Similar findings by Denton and Yousef (1976), Mlglavs and Jobling (1989) and Quinton and Blake (1990) also have pointed out that body weight during the hunger period is preserved by absorbing water to compensate for loss of organic material. In the present, study there were significant difference in body lipid between 2 and 3 groups compared to control group. Similar results have been reported in Pikeperch (Mattila et al., 2009), Atlantic halibut (Heide et al., 2006), Great sturgeon (Zhu et al., 2004), See bass (Adakly and Tasbozan, 2015) and Rainbow trout (Tasbozan et al., 2016). Figure 5 shows at the end of experiment, body protein was also affected by periods of food deprivation. In this regard, similar results have been reported by Wang et al. (2000) and Eroldogan et al. (2008). The usual response of fish to satisfy their energy needs during food deprivation is the use of lipid resources associated with protein. In fact, protein is used when the lipid resources are depleted (Henderson et al., 1988; Weatherley and Gill, 1987). Some researchers including Tian and Qin (2004), Ali et al. (2006), Iqbal et al. (2006), Mattilla et al. (2009),
Quinton and Blake (1990) reported no effect of food deprivation on the rate of body protein. The cause of the difference in the biochemical composition of the fish body between the present study and other studies on food deprivation and re-feeding probably relates to differences in experimental protocols, physiological conditions of fish, environmental conditions, species, age and size of fish body (Jobling and Baardivk, 1994; Jobling and Koskela, 1996).

In the present study there were no significant different between different group in liver lipid and glycogen levels. It seems that the rapid and complete renewal of liver glycogen after the re-feeding of fish under food deprivation is a tactic for the rapid storage of energy of food and then used to synthesis of body materials. Similar results were also evaluated in Rutilis rutilis (Mendez and Wieser, 1993) and Catostomus commersoni (Bandeen and Leatherland, 1997). In most species, liver glycogen is the first part used as a source of energy when it is reduced, fat stores are used as energy and when both sources are roughly reduced the muscle protein is mainly used for energy (Navarro and Gutierrez, 1995; Echevarria et al., 1997; Meton et al., 2003). In contrast to our study, Liu et al. (2011) performed a study on the effects of food deprivation and re-feeding in Acipenser sinensis. They stated that at the end of re-feeding, liver lipid levels were significantly higher in the group of 14 days of food deprivation than in other groups.

\section{CONCLUSION}

After the feeding period, groups that have experienced food deprivation showed complete compensatory growth. Because growth in these groups showed no significant difference compared with the control group. Also, the present results indicate that Sobaity fish have ability to achive optimal growth after food deprivation and refeeding periods.

\section{ACKNOWLEDGEMENT}

This study was financed by Khorramshahr Marine Science and Technology, Khorramshahr, Iran. We thank Nima Yazdi and Vahid Morshedi for their technical help throughout the experiment.

\section{REFERENCES}

Abdessalaam, T.Z.S., 1995. Marine Species of the Sultanate Oman: An Identification Guide. Muscat Printing Press, Ministry of Aquaculture and Fisheries, Marine Science and Fisheries Centre, Oman, Pages: 412. 
Adakly, A. and O. Tasbozan, 2015. The effects of different cycles of starvation and refeeding on growth and body composition on European sea bass (Dicentrarchus labrax). Turk. J. Fish. Aquat. Sci., 15: 419-427.

Ali, M., A. Nicieza and R.J. Wootton, 2003. Compensatory growth in fishes: A response to growth depression. Fish Fish., 4: 147-190.

Ali, M., R. Iqbal, S.A. Rana, M. Athar and F. Iqbal, 2006. Effect of feed cycling on specific growth rate, condition factor and RNA/DNA ratio of Labeo rohita. Afr. J. Biotechnol., 5: 1551-1556.

Bandeen, J. and J.F. Leatherland, 1997. Changes in the proximate composition of juvenile white suckers following re-feeding after a prolonged fast. Aquacult. Intl., 5: 327-337.

Boujard, T., C. Burel, F. Medale, G. Haylor and A. Moisan, 2000. Effect of past nutritional history and fasting on feed intake and growthin rainbow trout Oncorhynchus mykiss. Aquat. Living Resour., 13: 129-137.

Bull, C.D. and N.B. Metcalfe, 1997. Regulation of hyperphagia in response to varying energy deficits in overwintering juvenile Atlantic salmon. J. Fish Biol., 50: 498-510.

Chatakondi, N.G. and R.D. Yant, 2001. Application of compensatory growth to enhance production in channel catfish Ictalurus punctatus. J. World Aquacult. Soc., 32: 278-285.

Denton, J.E. and M.K. Yousef, 1976. Body composition and organ weights of Rainbow trout, Salmo gairdneri. J. Fish Biol., 8: 489-499.

Dobson, H.S. and R.M. Holmes, 1984. Compensatory growth in the rainbow trout, Salmo gairdneri Richardson. J. Fish. Biol., 25: 649-656.

Echevarryia, G., M. Martyinez-Bebia and S. Zamora, 1997. Evolution of biometric indices and plasma metabolites during prolonged starvation in European sea bass (Dicentrarchus labrax L.). Comp. Biochem. Physiol. Part A. Physiol., 118: 111-123.

Eroldogan, O.T., C. Suzer, O. Tasbozan and S. Tabakoglu, 2008. The effects of rate-restricted feeding regimes in cycles on digestive enzymes of gilthead sea-bream, Sparus aurata. Turk. J. Fish. Aquat. Sci., 8: 49-54.

Eroldogan, O.T., M. Kumlu, G.A. Kirisx and B. Sezer, 2006. Compensatory growth response of Sparus aurata following different starvation and refeeding protocols. Aquacult. Nutr., 12: 203-210.

Fischer, W. and G. Bianchi, 1984. FAO Species Identification Sheets for Fishery Purposes. Food and Agriculture Organization, Rome, Italy.
Foss, A., A.K. Imsland, E. Vikingstad, S.O. Stefansson and B. Norberg et al., 2009. Compensatory growth in Atlantic halibut: Effect of starvation and subsequent feeding on growth, maturation, feed utilization and flesh quality. Aquacult., 290: 304-310.

Frape, D., 1998. Equine Nutrition and Feeding. 2nd Edn., Wiley-Blackwell, Hoboken, New Jersey, USA., ISBN:9780632041053, Pages: 564.

Frings, C.S., T.W. Fendley, R.T. Dunn and C.A. Queen, 1972. Improved determination of total serum lipids by the sulfo-phospho-vanillin reaction. Clin. Chem., 18: 673-674.

Gaylord, T.G. and D.M. III Gatlin, 2000. Assessment of compensatory growth in channel catfish, Ictalurus punctatus $\mathrm{R}$. and associated changes in body condition indices. J. World Aquacult. Soc., 31: 326-336.

Guzel, S., H. Yazlak, K. Gullu and E. Ozturk, 2011. The effect of feed made from fish processing waste silage on the growth of rainbow trout (Oncorhynchus mykiss). Afr. J. Biotechnol., 10: 5053-5058.

Hayward, R.S., D.B. Noltie and N. Wang, 1997. Use of compensatory growth to double hybrid sunfish growth rates. Trans. Am. Fish. Soc., 126: 316-322.

Hayward, R.S., N. Wang and D.B. Noltie, 2000. Group holding impedes compensatory growth of hybrid sunfish. Aquacult., 183: 299-305.

Heide, A., A. Foss, S.O. Stefansson, I. Mayer and B. Norbery et al., 2006. Compensatory growth and fillet crude composition in juvenile Atlantic halibut: Effects of short term starvation periods and subsequent feeding. Aquaculture, 261: 109-117.

Henderson, P.A., R.H.A. Holmes and R.N. Bamber, 1988. Size-selective overwintering mortality in the sand smelt, Atherina boyeri Risso, and its role in population regulation. J. Fish Biol., 33: 221-233.

Hornick, J.L., C. van Eenaeme, O. Gerard, I. Dufrasne and L. Istasse, 2000. Mechanisms of reduced and compensatory growth. Domest. Anim. Endocrinol., 19: 121-132.

Houde, E.D. and R.C. Schekter, 1981. Growth rates, rations and cohort consumption of marine fish larvae in relation to prey concentrations. Rapp. PV. Reun. Cons. Intl. Explor. Mer., 178: 441-453.

Iqbal, F, M. Ali, K. Umer and S.A. Rana, 2006. Effect of feed cycling on specific growth rate, condition factor, body composition and RNA/DNA ratio of Cirrhinus mrigala. J. Appl. Sci. Environ. Manage., 10: 129-133.

Jobling, M. and B.M. Baardvik, 1994. The influence of environmental manipulations on inter- and intra-individual variation in food acquisition and growth performance of Arctic charr, Salielinus alpines. J. Fish Biol., 44: 1069-1087. 
Jobling, M. and I. Miglavs, 1993. The size of lipid depots-a factor contributing to the control of food intake in Arctic charr, Salvelinus alpines?. J. Fish Biol., 43: 487-489.

Jobling, M. and J. Koskela, 1996. Interindividual variations in feeding and growth in rainbow trout during restricted feeding and in a subsequent period of compensatory growth. J. Fish Biol., 49: 658-667.

Jobling, M., 1980. Effects of starvation on proximate chemical composition and energy utilization of plaice, Pleuronectes platessa L. J. Fish Biol., 17: 325-334.

Jobling, M., 1994. Fish Bioenergetics. Springer, Netherlands, ISBN:9780412580901, Pages: 309.

Johansen, S.J.S., M. Ekli, B. Stangnes and M. Jobling, 2001. Weight gain and lipid deposition in Atlantic salmon, Salmo salar, during compensatory growth: Evidence for lipostatic regulation?. Aquacult. Res., 32: 963-974.

Kankanen, M. and J. Pirhonen, 2009. The effect of intermittent feeding on feed intake and compensatory growth of whitefish Coregonus lavaretus L. Aquaculture, 288: 92-97.

Liu, W., Q.W. Wei, H. Wen, M. Jiang, F. Wu and Y. Shi, 2011. Compensatory growth in juvenile Chinese sturgeon (Acipenser sinensis): Effects of starvation and subsequent feeding on growth and body composition. J. Applied Ichthyol., 27: 749-754.

Lo, S., J.C. Russell and A.W. Taylor, 1970. Determination of glycogen in small tissue samples. J. Applied Physiol., 28: 234-236.

Maclean, A. and N.B. Metcalfe, 2001. Social status, access to food and compensatory growth in juvenile Atlantic salmon. J. Fish Biol., 58: 1331-1346.

Mattila, J., J. Koskela and J. Pirhonen, 2009. The effect of the length of repeated feed deprivation between single meals on compensatory growth of pikeperch Sander lucioperca. Aquacult., 296: 65-70.

Mendez, G. and W. Wieser, 1993. Metabolic responses to food deprivation and refeeding in juveniles of Rutilis rutilis (Teleostei: Cyprinidae). Environ. Biol. Fishes, 36: 73-81.

Metcalfe, N.B. and J.E. Thorpe, 1992. Anorexia and defended energy levels in over-wintering juvenile salmon. J. Anim. Ecol., 61: 175-181.

Metcalfe, N.B. and P. Monaghan, 2001. Compensation for a bad start: Grow now, pay later?. Trends Ecol. Evol., 16: $254-260$.

Meton, I., F. Fernandez and A.I. Baanante, 2003. Short-and long-term effects of refeeding on key enzyme activities in glycolysis-gluconeogenesis in the liver of gilthead seabream (Sparus aurata). Aquacult., 225: 99-107.
Mlglavs, I. and M. Jobling, 1989. Effects of feeding regime on food consumption, growth rates and tissue nucleic acids in juvenile Arctic charr, Salvelinm alpinus, with particular respect to compensatory growth. J. Fish Biol., 34: 947-957.

Navarro, I. and J. Gutierrez, 1995. Fasting and Starvation. In: Biochemistry and Molecular Biology of Fishes: Metabolic Biochemistry, Hochachka, P.W. and T.P. Mommsen (Eds.). Vol. 2, Elsevier, Amsterdam, Netherlands, pp: 393-434.

Nicieza, A.G. and N.B. Metcalfe, 1997. Growth compensation in juvenile Atlantic salmon: Responses to depressed temperature and food availability. Ecol., 78: 2385-2400.

Nikki, J., J. Pirhonen, M. Jobling and J. Karjalainen, 2004. Compensatory growth in juvenile rainbow trout, Oncorhynchus mykiss (walbaum), held individually. Aquaculture, 235: 285-296.

Oh, S.Y., C.H. Noh and S.H. Cho, 2007. Effect of restricted feeding regimes on compensatory growth and body composition of red sea bream, Pagrus major. J. World Aquacult. Soc., 38: 443-449.

Qian, X., Y. Cui, B. Xiong and Y. Yang, 2000. Compensatory growth, feed utilization and activity in gibel carp, following feed deprivation. J. Fish Biol., 56: $228-232$.

Quinton, J.C. and R.W. Blake, 1990. The effect of feed cycling and ration level on the compensatory growth response in rainbow trout, Oncorhynchus mykiss. J. Fish. Biol., 37: 33-41.

Ribeiro, F.F. and M.Y. Tsuzuki, 2010. Compensatory growth responses in juvenile fat snook, Centropomus parallelus Poey, following food deprivation. Aquacult. Res., 41: e226-e233.

Russell, N.R. and R.G. Wootton, 1992. Appetite and growth compensation in the European minnow Phoxinus phoxinus ( Cyprinidae) following short period of food restriction. Environ. Biol. Fish., 34: 277-285.

Sevgili, H., B. Hossu, Y. Emre and M. Kanyylmaz, $2013 \mathrm{~b}$. Compensatory growth following various time lengths of restricted feeding in rainbow trout (Oncorhynchus mykiss) under summer conditions. J. Appl. Ichthyol., 29: 1330-1336.

Sevgili, H., B. Hossu, Y. Emre and M. Kanyylmaz, 2013a. Effect of various lengths of single phase starvation on compensatory growth in rainbow trout under summer conditions (Oncorhynchus mykiss). Turk. J. Fish. Aquat. Sci., 13: 465-477.

Sun, L., H. Chen, L. Huang, Z. Wang and Y. Yan, 2006. Growth and energy budget of juvenile cobia (Rachycentron canadum) relative to ration. Aquaculture, 257: 214-220. 
Tasbozan, O., Y. Emre, M.A. Gokce, C. Erbas and F. Ozcan et al., 2016. The effects of different cycles of starvation and re-feeding on growth and body composition in rainbow trout (Oncorhynchus mykiss, Walbaum, 1792). J. Appl. Ichthyol., 32: 583-588.

Tian, X. and J.G. Qin, 2003. A single phase of food deprivation provoked compensatory growth in barramundi, Lates calcarifer. Aquaculture, 224: 169-179.

Tian, X. and J.G. Qin, 2004. Effects of previous ration restriction on compensatory growth in barramundi, Lats calcarifer. Aquaculture, 235: 273-283.

Turano, M.J., R.J. Borski and H.V. Daniels, 2007. Compensatory growth of pond-reared hybrid striped bass, Morone chrysops $\times$ Morone saxatilis, fingerlings. J. World Aquacult. Soc., 38: 250-261.

Turano, M.J., R.J. Borski and H.V. Daniels, 2008. Effects of cyclic feeding on compensatory growth of hybrid striped bass (Morone chrysops $\times$ M. saxitilis) foodfish and water quality in production ponds. Aquacult. Res., 39: 1514-1523.

Wang, Y., C. Li, J.G. Qin and H. Han, 2009. Cyclical feed deprivation and refeeding fails to enhance compensatory growth in Nile Tilapia, Oreochromis niloticus L. Aquacult. Res., 40: 204-210.

Wang, Y., Y. Cui, Y. Yang and F. Cai, 2005. Partial compensatory growth in hybrid tilapia Oreochromis mossambicus $\times O$. niloticus following food deprivation. J. Appl. Ichthyol., 21: 389-393.

Wang, Y., Y. Cui, Y. Yang, F. Cai and F.S. Cai, 2000. Compensatory growth in hybrid tilapia (Oreochromis mossambicus $O$. niloticus) reared in sea water. Aquaculture, 189: 101-108.

Weatherley, A.H. and H.S. Gill, 1987. The Biology of Fish Growth. Academic Press, London, Pages: 443.

Wicks, B.J. and D.J. Randall, 2002. The effect of feeding and fasting on ammonia toxicity in juvenile rainbow trout Oncorhynchus mykiss. Aqua. Toxicol., 59: $71-82$.
Wieser, W., G. Krumschnabel and J.P. Ojwang-Okwor, 1992. The energetic of starvation and growth after refeeding in juveniles of three cyprinid species. Environ. Biol. Fish., 33: 63-71.

Williams, S., 1984. Official Methods of Analysis of the Association of Official Analytical Chemists. 14th Edn., The Association America, USA., ISBN:9780935584240, Pages: 1141.

Wilson, P.N. and D.F. Osbourn, 1960. Compensatory growth after undernutrition in mammals and birds. Biol. Rev., 35: 324-361.

Wu, L., S. Xie, X. Zhu, Y. Cui and R.J. Wootton, 2002. Feeding dynamics in fish experiencing cycles of feed deprivation: A comparison of four species. Aquacult. Res., 33: 481-489.

Xie, S., X. Zhu, Y. Cui, R.J. Wootton,W. Lei and Y. Yang, 2001. Compensatory growth in the gibel carp following feed deprivation: Temporal patterns in growth, nutrient deposition, feed intake and body composition. J. Fish Biol., 58: 999-1009.

Zhu, X., S. Xie, W. Lei, Y. Cui, Y. Yang and R.J. Wootton, 2005. Compensatory growth in the Chinese long snout catfish, Leiocassis longirostris, following feed deprivation: Temporal patterns in growth, nutrient deposition, feed intake and body composition. Aquaculture, 248: 307-314.

Zhu, X., S. Xie, Z. Zou, W. Lei and Y. Cui et al., 2004. Compensatory growth and food consumption in Gibel carp, Carassius Auratus gibelio and Chinese longsnout catfish, Leiocassis longirostris, experiencing cycles of feed deprivation and re-feeding. Aquacult., 241: 235-247.

Zhu, X., Y. Cui, M. Ali and R.J. Wootton, 2001. Comparison of compensatory growth responses of juvenile three-spined stickleback and minnow following similar food deprivation protocols. J. Fish Biol., 58: 1149-1165. 